\title{
THE LEVEL OF MOTOR ABILITY OF SOCCER ATHLETES IN THE FC UNY ACADEMY IN 2020
}

\author{
Yudanto $^{1^{*}}$, Tifa Alfian ${ }^{1}$ \\ ${ }^{1}$ Pendidikan Olahraga, Fakultas Ilmu Keolahragaan Universitas Negeri Yogyakarta. Jl. Colombo No. 1, \\ Karangmalang Depok, Sleman, Yogyakarta, Indonesia \\ *yudanto@uny.ac.id, tifaalfian97@gmail.com
}

\begin{abstract}
This research aims to find out the level of motor ability of the Football Athlete at the FC UNY Academy in 2020. The purpose of this study was to determine the level of motor ability of the Football Athlete at the FC UNY Academy in 2020. This research was a quantitative research with survey method. The research population was 24 Soccer players from Yogyakarta State University FC Academy in 2020. The test instruments used in this study are using the Barrow motor ability test which includes: Standing broad jump, Soft ball throw, Zigzag run, Wall pass , Medicine ball put , Running 60 yard dash. Measuring instruments used to measure are stopwatch and meter. Data analysis techniques using descriptive analysis with percentage. The results of the research on the motor ability level of Football Athletes at the FC UNY Academy in 2020 as the following: 2 athletes $(8.33 \%)$ are in very high category, 2 athletes $(8.33 \%)$ are in high category, 10 athletes $(41.67 \%)$ are in moderate category, 8 athletes $(33.33 \%)$ are in poor category, 2 athletes $(8.33 \%)$ are in very poor category.
\end{abstract}

Keywords: Motor Ability, Football Athletes, FC UNY Academy

\section{TINGKAT KEMAMPUAN MOTORIK ATLET SEPAKBOLA DI AKADEMI FC UNY TAHUN 2020}

\begin{abstract}
Abstrak
Penelitian ini bertujuan untuk mengetahui seberapa tingkat kemampuan motorik Atlet Sepakbola Di Akademi FC UNY Tahun 2020. Tujuan dari penelitian ini yaitu untuk mengetahui tingkat kemampuan motorik Atlet Sepakbola Di Akademi FC UNY Tahun 2020. Penelitian ini merupakan penelitian kuantitatif. Metode penelitian yang digunakan adalah metode survei dengan teknik tes pengukuran untuk mendapatkan data. Populasi yang digunakan dalam penelitian ini adalah Atlet Sepakbola Di Akademi FC UNY Tahun 2020 yang berjumlah 24 orang. Instrumen tes yang digunakan dalam penelitian ini yaitu menggunakan tes Barrow motor ability test yang meliputi: Standing broad jump, Soft ball throw, Zig-zag run, Wall pass, Medicine ball put, Lari 60 yard dash. Alat ukur yang digunakan untuk mengukur adalah stopwatch dan meteran. Teknik analisis data menggunakan analisis deskriptif dengan persentase. Hasil dari penelitian tingkat kemampuan motorik Atlet Sepakbola Di Akademi FC UNY Tahun 2020 sebagai berikut bahwa 2 atlet $(8,33 \%)$ berada pada kategori sangat tinggi, 2 atlet $(8,33 \%)$ berada pada kategori tinggi, 10 atlet $(41,67 \%)$ berada pada kategori sedang, 8 atlet $(33,33 \%)$ berada pada kategori kurang, 2 atlet $(8,33 \%)$ berada pada kategori sangat kurang.
\end{abstract}

Kata Kunci : Kemampuan Motorik, Atlet Sepakbola, Akademi FC UNY

\section{PENDAHULUAN}

Permainan sepakbola adalah permainan regu atau tim yang menggunakan bola besar dengan peraturan yang sudah baku. Untuk menjadi pemain yang berkualitas baik, diperlukan penguasaan teknik-teknik dasar bermain sepakbola. Teknik dasar sepakbola 
terdiri dari teknik passing, dribbling, shooting, heading, dan kontrol bola (Timo Scheunemann, 2005:33-75).

Tujuan pemain melakukan aktifitas permainan sepakbola berawal dari yang bersifat hiburan untuk mengisi waktu luang yang akhirnya berkembang luas, seperti memelihara kesegaran jasmani, menjadi pemain yang profesional, mencapai prestasi yang tinggi dan mengharumkan nama daerah. Cabang olahraga sepakbola merupakan permainan invasi, dimana setiap regu saling menyerang dalam penguasaan bola dengan tujuan untuk memasukkan bola ke gawang lawan dan mempertahankan gawang sendiri agar tidak kemasukan bola. Salah satu regu dinyatakan menang apabila berhasil memasukkan bola sebanyak-banyaknya ke gawang lawannya sampai waktu berakhirnya pertandingan. Prinsip dalam sepakbola adalah membuat gol sebanyak mungkin ke gawang lawan dan mencegah jangan sampai lawan membuat gol ke gawang sendiri. Dalam sepakbola diperlukan juga kerja sama tim dalam melakukan penyerangan ataupun pada saat bertahan. Kemampuan menguasai permainan sepakbola adalah menendang bola, menerima bola, menggiring bola, menyundul bola, gerak tipu dan penjaga gawang.

Tujuan dari permainan sepakbola yaitu untuk mediator dalam mendidik anak agar tumbuh dan berkembang semangat persaingan (competition), kerjasama (cooperation), interaksi sosial (social interaction), dan pendidikan moral (moral education) (Sucipto, 2000: 8). Sebagai unsur kerja yang mendasari segala unsur kemampuan gerak dalam pendidikan jasmani adalah koordinasi, kecepatan, agilitas/ kelincahan, keseimbangan dan power/ daya ledak (Harsuki, 2003: 54).

Kemampuan motorik adalah kapasitas seseorang yang berkaitan dengan pelaksanaan dan peragaan suatu keterampilan yang relatif melekat setelah masa kanak-kanak (Rusli Lutan, 1988: 96). Kemampuan motorik merupakan salah satu kemampuan yang perlu dimiliki oleh atlet. Hal ini menjadi penting mengingat, pada umumnya setiap aktivitas kehidupan manusia tidak terlepas dari gerak. Manusia melakukan aktivitas gerak sesuai dengan kemampuan mereka sendiri. Belajar gerak dasar yang paling ideal terjadi pada fase anak- anak. Di dalam kehidupan ini gerak sangat dibutuhkan oleh setiap manusia untuk melakukan aktivitas, penguasaan gerak sejak masa kecil akan membantu kita menjadi manusia terampil di kehidupan yang akan datang sehingga dapat tercapai kehidupan yang lebih baik.

Proses motorik terjadi atas kerja beberapa bagian tubuh, saraf, otak dan juga otot, sehingga terjadi gerakan baik gerak reflek atau gerak tak disadari maupun yang disadari. Fungsi sel saraf motorik adalah mengirim impuls dari sistem saraf pusat sampai ke otot, sehingga ujung akson mengeluarkan zat kimia sehingga otot berkontraksi dan terjadi proses motoris. Kemampuan motorik adalah kemampuan seseorang untuk berbagai nomor olahraga yang diajarkannya dan menandakan kemampuan keterampilan umum. Kemampuan motorik atau kemampuan gerak tersebut merupakan salah satu faktor yang berpengaruh dalam pencapaian prestasi olahraga.

Pentingnya kemampuan motorik karena kemampuan gerak merupakan bagian dari ranah psikomotorik. Kemampuan motorik berhubungan dengan kualitas gerak atau cara melakukan gerakan. Adapun unsur-unsur kemampuan motorik terdiri dari: kekuatan, kecepatan, power, ketahanan, keseimbangan, fleksibilitas, dan koordinasi. Kemampuan motorik anak akan berkembang apabila didukung dengan latihan-latihan secara rutin dan kontinyu (Imam Yanuar, 2010: 10). Hal ini menjadi penting mengingat masing-masing unit gerak yang dilakukan oleh anak akan terkoordinasi dengan baik. Sebaliknya, apabila anak kurang melakukan gerak dalam permainan olah raga maka secara tidak langsung akan menghambat perkembangan kemampuan motoriknya

Berdasarkan hasil pengamatan peneliti ketika klub akademi sedang berlangsung, dengan rincian klub ini berlatih 3 kali dalam semiggu yaitu Senin, rabu, Jum'at dan dimulai 
pukul 15.30 - 17.30 WIB, untuk latihan hari senin dilaksanakan di lingkungan Stadion Atletik dan Sepakbola UNY sedangkan latihan hari Rabu dan Jumat dilaksankan di Lapangan Sepakbola NDB Angkasa Pura. Peneliti menemukan masalah pada atlet sepakbola di Akademi FC UNY. Masalah yang di dapat ketika peneliti mengamati atlet sepakbola Akademi FC UNY melakukan latihan saat sesi game bahwa terlihat beberapa pemain mengalami kesulitan dalam menerima materi latihan teknik bermain sepakbola. Namun ada beberapa pemain yang tampak sudah terlihat terampil dalam berbagai teknik dasar sepakbola, hal tersebut karena para atlet sepakbola di akademi FC UNY tidak semuanya mengawali belajar sepakbola di klub SSB, ada yang baru di usia SMP baru belajar bermain sepakbola bahkan ada juga yang di usia SMA baru memulai belajar tentang bermain sepakbola.

Tabel 1. Tingkat dimulainya atlet belajar bermain sepakbola

\begin{tabular}{clll}
\hline No & Usia Belajar Sepakbola & Frekuensi & Presentase \\
\hline 1. & SD (SSB) & 10 & $33,33 \%$ \\
\hline 2. & SMP (SSB) & 9 & $30,00 \%$ \\
\hline 3. & SMP (NON SSB) & 6 & $20,00 \%$ \\
\hline 4. & SMA (NON SSB) & 5 & $16,67 \%$ \\
\hline & Jumlah & 30 & $100 \%$ \\
\hline
\end{tabular}

Gerakan-gerakan pemain ketika bermain sepakbola terlihat masih kaku. Contoh yang terlihat yaitu pada unsur kelincahan (agillity) beberapa pemain, ketika pemain menggiring bola sambil berlari dan dihadang oleh pemain lawan justru sering terjadi tabrakan. Kemudian dari unsur daya ledak pada kaki terlihat beberapa hasil tendangan mengoper (passing) pendek maupun jauh dan tembakan (shooting) yang kurang keras sehingga bola tidak sampai pada target. Padahal terciptanya peluang shooting didukung oleh kecepatan dan ketepatan bola ketika passing. Dari hasil pengamatan tersebut terlihat bahwa unsurunsur kemampuan motorik yang dimiliki masing-masing pemain perlu diketahui oleh pelatih. Karena selain faktor latihan, kemampuan motorik merupakan modal utama untuk mencapai seorang pemain sepakbola yang terampil.

Kemampuan motorik bersifat alami atau bawaan sehingga merupakan modal dasar pemain untuk belajar gerak mencapai tingkat terampil dalam permainan sepakbola. Oleh karena itu faktor kemampuan motorik yang dimiliki pemain perlu diperhatikan. Hal ini mengingat, setiap atlet mempunyai kemampuan motorik yang berbeda-beda dalam bermain sepakbola. Sehingga, meskipun atlet melakukan program latihan yang sama akan tetapi pencapaian prestasinya berbeda-beda tergantung pada kemampuan motorik yang dimiliki masing-masing atlet sepakbola

Melihat pentingnya kemampuan motorik pemain sebagai modal awal untuk menyalurkan bakat sepakbola melalui kegiatan sekolah sepakbola untuk mencapai tingkat pemain sepakbola yang terampil, maka peneliti ingin meneliti "Tingkat Kemampuan Motorik Atlet Sepakbola di Akademi FC UNY tahun 2020".

\section{METODE}

\section{Jenis penelitian}

Penelitian ini adalah penelitian deskriptif kuantitatif. Penelitian deskriptif kuantitatif adalah penelitian yang menggabarkan kondisi sekarang dan tanpa pengujian hipotesis. Metode yang digunakan pada penelitian ini adalah metode survei. Teknik pengumpulan data menggunakan tes dan pengukuran. Sebagaimana yang sudah dijelaskan diatas, penelitian ini bertujuan untuk mengetahui seberapa tinggi tingkat kemampuan motorik atlet sepakbola di akdemi FC UNY tahun 2020. 


\section{Waktu dan Tempat Penelitian}

Penelitian ini dilaksanakan di Lapangan NDB Angkasa Pura 1 yang beralamat di Jl. Janti, Kec. Depok, Kab. Sleman, Daerah Istimewa Yogyakarta 55189 (sebelah selatan jalan Jogja-Solo). Waktu penelitian dilaksanakan pada hari Rabu, 11 Maret 2020, pukul 15.00 WIB - selesai.

\section{Subjek Penelitian}

Subjek dalam penelitian ini adalah sebagian Atlet Sepakbola di Akdemi FC UNY yang berjumlah 24 atlet. Teknik yang digunakan dalam pengambilan sampel adalah teknik simple random sampling.

\section{Data, Intrumen, dan Teknik Pengumpulan Data}

Instrumen merupakan salah satu langkah penting dalam sebuah penelitian. Instrumen berfungsi sebagai alat bantu dalam mengumpulkan data yang diperlukan dalam sebuah penelitian agar pekerjaanya bisa lebih mudah dan mendapatkan hasil yang baik, lengkap dan sistematis sehingga datanya mudah untuk diolah. Instrumen penelitian ini menggunakan instrumen berupa tes kemampuan motorik kasar siswa adapun instrumen yang digunakan oleh Nurhasan (2004: 6: 8) adalah Borrow Motor Ability yang meliputi standing broad jump, soft ball throw, zig-zag run, wall pass, medicine ball put, dan lari 60 yard dash (50 $m)$.

Tabel 2. Hasil Uji Validitas

\begin{tabular}{lll}
\hline No & Komponen Tes & Nilai Validitas \\
\hline 1 & Standing Broad Jump & 0,774 \\
\hline 2 & Soft ball Throw & 0,811 \\
\hline 3 & Zig-Zag Run & 0,558 \\
\hline 4 & Wall Pass & 0,460 \\
\hline 5 & Medicine Ball Put & 0,761 \\
\hline 6 & Lari 60 Yard Dash & 0,557 \\
\hline
\end{tabular}

Tabel 3. Hasil Uji Reliabilitas

\begin{tabular}{lll}
\hline No & Komponen Tes & Nilai Reliabilitas \\
\hline 1 & Standing Broad Jump & 0,643 \\
\hline 2 & Soft ball Throw & 0,626 \\
\hline 3 & Zig-Zag Run & 0,729 \\
\hline 4 & Wall Pass & 0,760 \\
\hline 5 & Medicine Ball Put & 0,649 \\
\hline 6 & Lari 60 Yard Dash & 0,729 \\
\hline
\end{tabular}

Adapan tahapan mengumpulkan data yang dilakukan dalam penelitian ini adalah sebagai berikut: 1) Mempersiapkan sarana dan prasarana yang akan digunakan untuk tes kemampuan motoric; 2) Mengumpulkan, menyiapkan dan pemanasan, serta memberikan penjelasan pelaksanaan tes kemampuan motorik pada atlet akademi FC UNY. 3) Setelah itu atlet akademi FC UNY dibagi menjadi 3 kelompok, masing-masing kelompok selanjutnya melakukan tes kemampuan motorik dengan didampingi 6 petugas. Masing-masing atlet melakukan tes secara bergantian sesuai dengan urutan yang sudah ditentukan, yaitu dimulai dari tes power tungkai, power lengan, kelincahan, koordinasi mata dan tangan, power lengan, dan kecepatan; 4) Masing-masing hasil tes yang didapatkan siswa dicatat dalam lembar tes yang sudah dipersiapkan. 


\section{Teknik Analisis Data}

kemampuan motorik merupakan data kasar. Hasil kasar yang diperoleh dari tes kemampuan motorik kemudian diubah ke dalam bentuk T-Score. Setelah diperoleh hasil TScore kemudian dijumlahkan hasil dari masing-masing item tes/kategori dan setelah sudah dijumlahkan kemduian dilanjutkan dengan mengkoversikan ke dalam kategori kemampuan motorik.

Rumus T-score untuk zig-zag run dan lari 60 yard dash. Tes ini menggunakan satuan waktu sehingga semakin sedikit waktu yang di dapat, semakin bagus juga hasil yang diperoleh. Rumus T-scorenya sebagai berikut:

$$
\mathrm{T}-\text { score }=50+\left(\frac{M-X}{S D}\right) \times 10
$$

Rumus T-Score untuk tes standing board jump, soft ball throw, wall pass, dan medicine ball put. Perhitungan dengan satuan, semakin banyak angka satuan yang diperoleh maka semakin bagus hasil yang diperoleh. Untuk rumus T-Score sebagai berikut:

$$
\mathrm{T} \text {-score }=\mathbf{5 0}+\left(\frac{X-M}{S D}\right) \times 10
$$

keterangan :

$\mathrm{M}=$ Mean (nilai rata-rata)

$\mathrm{X}=$ Skor yang diperoleh

$\mathrm{SD}=$ Standar Deviasi

Penghitungan T-Score dari keenam item tersebut dijumlahkan dan dibagi dengan jumlah item tes yang ada, hasil dari pembagian tersebut dijadikan dasar menentukan tingkat kemampuan motorik atlet. Tingkat kemampuan tersebut harus dibuatkan kategori menjadi 5 penilaian, yaitu: sangat tinggi, tinggi, sedang, kurang, sangat kurang menggunakan rumus sebagai berikut (Saifuddin Azwar, 2005: 108).

Tabel 4. Kategori Kemampuan Motorik

\begin{tabular}{ll}
\hline Interval skor kemampuan motorik & kategori \\
\hline$X \geq M+1,5 \mathrm{SD}$ & Sangat tinggi \\
\hline$M+0,5 \mathrm{SD} \leq \mathrm{X}<\mathrm{M}+1,5 \mathrm{SD}$ & Tinggi \\
\hline $\mathrm{M}-0,5 \mathrm{SD} \leq \mathrm{X}<\mathrm{M}+0,5 \mathrm{SD}$ & Sedang \\
\hline $\mathrm{M}-0,5 \mathrm{SD} \leq \mathrm{X}<\mathrm{M}-0,5 \mathrm{SD}$ & Kurang \\
\hline $\mathrm{X} \geq \mathrm{M}-1,5 \mathrm{SD}$ & Sangat kurang \\
\hline
\end{tabular}

Keterangan:

$\mathrm{X}$ : Skor yang diperoleh

SD : Standar Deviasi

$\mathrm{M}:$ Mean

Untuk mengetahui jumlah masing-masing kategori kemampuan motorik atlet sepakbola di akademi FC UNY, menggunakan rumus persentase dari Anas Sudijono (1992: 40). Adapun sebagai berikut.

$$
\mathrm{P}=\frac{F}{N} \times 100 \%
$$

Keterangan:

$\mathrm{P}=$ Persentase

$\mathrm{F}=$ Frekueansi

$\mathrm{N}=$ Jumlah Atlet 


\section{HASIL PENELITIAN}

Penelitian ini menggunakan analisis T-score. Data kemampuan motorik atlet sepakbola akademi FC UNY didapatkan melalui tes, tes yang diguinakan adalah Barrow Motor Ability Test yang meliputi: Standing Broadd Jump, Soft Ball Throw, Zig-zag Run, Wall Pass, Medicine Ball Put, Lari 60 Yard Dash. Kategori tingkat kemampuan motorik atlet sepakbola akademi FC UNY dikategorikan menjadi 5 tingkat yaitu sangat tinggi, tinggi, sedang, kurang, sangat kurang. Hasil analisis data dalam penelitian ini meliputi hasil keseluruhan kemampuan motorik dan masing-masing aspek tes kemampuan motorik. Hasil analisi data penelitian ini sebagai berikut.

\section{Kemampuan Motorik Secara Keseluruhan}

Hasil skor kemampuan motorik atlet sepakbola akademi FC UNY secara keseluruhan diperoleh skor maksimal sebesar 407,84; skor minimal sebesar 227,10; mean (rata-rata) 300; median sebesar 302,22; modus sebesar 227,10; dan standar deviasi sebesar 40,94.

Kemampuan motorik atlet sepakbola akademi FC UNY dikategorikan menjadi 5 kategori yaitu sangat tinggi, tinggi, sedang, kurang, sangat kurang. Dari hasil perhitungan yang sudah dilakukan maka hasil analisis data yang sudah dilakukan adalah sebagai berikut:

Tabel 5. Distribusi kemampuan motorik atlet sepakbola

\begin{tabular}{|c|c|c|c|c|c|}
\hline No & \multicolumn{2}{|c|}{ Rumus } & Kategori & Frekuensi & Persentase $(\%)$ \\
\hline 1 & 374.88 & $x>374.88$ & Sangat Tinggi & 2 & 8.33 \\
\hline 2 & 332.86 & $332.86-374.88$ & Tinggi & 2 & 8.33 \\
\hline 3 & 290.85 & $290.85-332.85$ & Sedang & 10 & 41.67 \\
\hline 4 & 248.83 & $248.83-290.84$ & Kurang & 8 & 33.33 \\
\hline 5 & 243.17 & $x<243.17$ & Sangat kurang & 2 & 8.33 \\
\hline \multicolumn{4}{|c|}{ Jumlah } & 24 & 100 \\
\hline
\end{tabular}

Dari tabel di atas, diperoleh tingkat kemampuan motorik atlet sepakbola di akademi FC UNY secara keseluruhan diketahui bahwa 2 atlet $(8,33 \%)$ berada pada kategori sangat tinggi, 2 atlet $(8,33 \%)$ berada pada kategori tinggi, 10 atlet $(41,67 \%)$ berada pada kategori sedang, 8 atlet $(33,33 \%)$ berada pada kategori kurang, 2 atlet $(8,33 \%)$ berada pada kategori sangat kurang. Dari tabel di atas disajikan dalam bentuk diagram batang sebagai berikut:

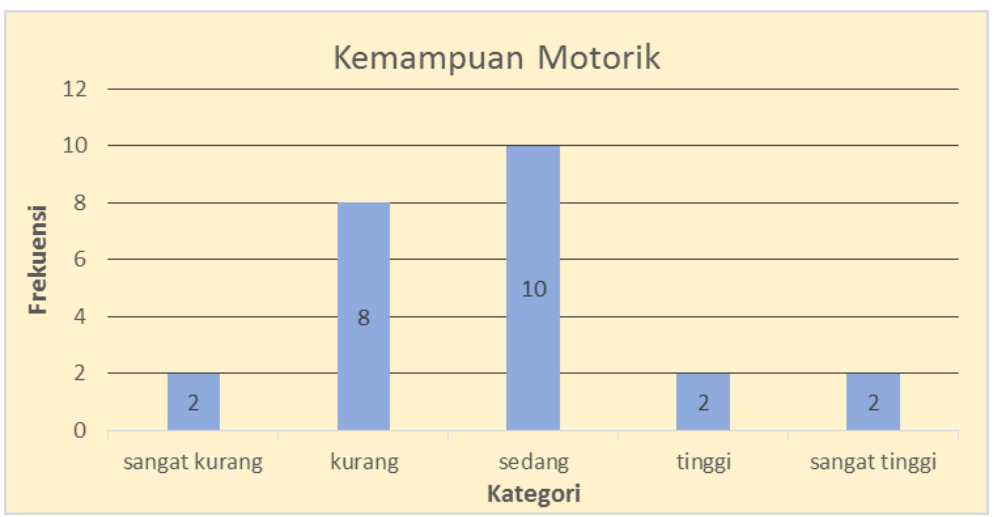

Gambar 1. Diagram Kemampuan Motorik Keseluruhan

Untuk menentukan hasil kemampuan motorik secara keseluruhan yang terdiri dari 6 macam tes yang digunakan yaitu Standing Broadd Jump, Soft Ball Throw, Zig-zag Run, Wall Pass, Medicine Ball Put, Lari 60 Yard Dash. Berikut hasil analisis data dari 6 macam komponen tes kemampuan dasar motorrik atlet sepakbola di akademi FC UNY. 


\section{Komponen Power Otot Tungkai Diukur dengan Tes Standing Broad Jump}

Berdasarkan hasil tes standing broad jump diperoleh skor maksimal sebesar 67,01; skor minimal sebesar 31,49; mean (rata-rata) 50,00; median sebesar 48,15; modus sebesar 36,69; dan standar deviasi sebesar 10,00. Berdasarkan rumus kategori yang telah ditentukan, analisis data hasil kemampuan motoriik atlet sepakbola di Akademi FC UNY ditinjau dari tes kekuatatan otot tungkai adalah sebagai berikut:

Tabel 6. Distribusi kemampuan Power Otot Tungkai

\begin{tabular}{|c|c|c|c|c|c|}
\hline No & \multicolumn{2}{|c|}{ Rumus } & Kategori & Frekuensi & Persentase (\%) \\
\hline 1 & 65.00 & $>65$ & Sangat Tinggi & 2 & 8.33 \\
\hline 2 & 55.00 & $55-65$ & Tinggi & 6 & 25.00 \\
\hline 3 & 45.00 & $45-54$ & Sedang & 7 & 29.17 \\
\hline 4 & 35.00 & $35-44$ & Kurang & 8 & 33.33 \\
\hline 5 & $\leq 35$ & $<35$ & Sangat kurang & 1 & 4.17 \\
\hline \multicolumn{4}{|c|}{ Jumlah } & 24 & 100.00 \\
\hline
\end{tabular}

Berdasarkan dari hasil tabel di atas maka dapat dijelaskan secarfa keseluruhan hasil dari kemampuan power otot tungkai atlet sepakbola di akademi FC UNY sebanyak 2 atlet $(8,33 \%)$ berada pada kategori sangat tinggi, 6 atlet $(25,00 \%)$ berada pada kategori tinggi, 7 atlet $(29,17 \%)$ berada pada kategori sedang, 8 atlet $(8,33 \%)$ berada pada kategori kurang, 1 atlet $(4,17 \%)$ berada pada kategori sangat kurang. Jadi dapat disimpulkan bahwa mayoritas kekuatan otot tungkai atlet sepakbola di Akademi FC UNY berada pada kategori kurang sebesar 33,33\%. Berdasarkan hasil diatas disajikan dalam bentuk diagram batang sebagai berikut:

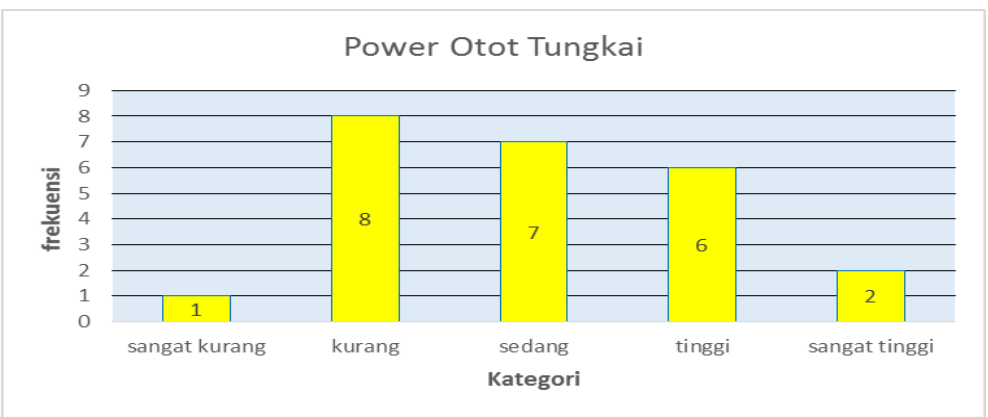

Gambar 2. Diagram Kemampuan Power Otot Tungkai

\section{Komponen Power Otot Lengan dan Bahu Diukur dengan Tes Soft Ball Throw}

Berdasarkan hasil tes Soft Ball Throw diperoleh skor maksimal sebesar 78,07; skor minimal sebesar 33,23; mean (rata-rata) 50,00; median sebesar 49,89; modus sebesar 51,05; dan standar deviasi sebesar 10,00. Berdasarkan rumus kategori yang telah ditentukan, analisis data hasil kemampuan motorik atlet sepakbola di Akademi FC UNY ditinjau dari tes kemampuan power otot lengan dan bahu adalah sebagai berikut:

Tabel 7. Distribusi Kemampuan Power Otot Lengan dan Bahu

\begin{tabular}{|c|c|c|c|c|c|}
\hline No & \multicolumn{2}{|c|}{ Rumus } & Kategori & Frekuensi & Persentase $(\%)$ \\
\hline 1 & 65.00 & $>65$ & Sangat Tinggi & 2 & 8.33 \\
\hline 2 & 55.00 & $55-65$ & Tinggi & 3 & 12.50 \\
\hline 3 & 45.00 & $45-54$ & Sedang & 12 & 50.00 \\
\hline 4 & 35.00 & $35-44$ & Kurang & 6 & 25.00 \\
\hline 5 & $\leq 35$ & $<35$ & Sangat kurang & 1 & 4.17 \\
\hline \multicolumn{4}{|c|}{ Jumlah } & 24 & 100.00 \\
\hline
\end{tabular}


Berdasarkan dari hasil tabel di atas maka dapat dijelaskan secarfa keseluruhan hasil dari kemampuan power otot lengan dan bahu atlet sepakbola di akademi FC UNY sebanyak 2 atlet $(8,33 \%)$ berada pada kategori sangat tinggi, 3 atlet $(12,50 \%)$ berada pada kategori tinggi, 12 atlet $(50,00 \%)$ berada pada kategori sedang, 6 atlet $(25,00 \%)$ berada pada kategori kurang, 1 atlet $(4,17 \%)$ berada pada kategori sangat kurang. Jadi dapat disimpulkan bahwa mayoritas kekuatan otot lengan dan bahu atlet sepakbola di Akademi FC UNY berada pada kategori sedang sebesar 50,00 \%. Berdasarkan hasil diatas disajikan dalam bentuk diagram batang sebagai berikut:

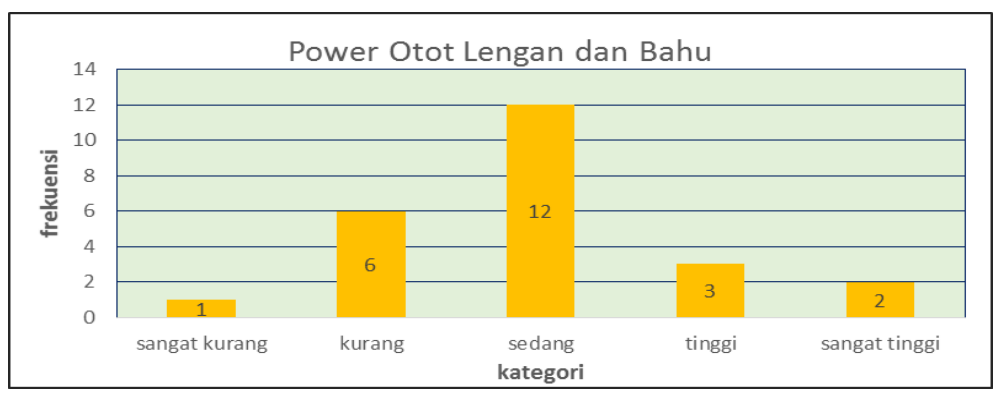

Gambar 3. Diagram kemampuan Power Otot Lengan dan Bahu

\section{Komponen Kelincahan Diukur dengan Tes Zig-Zag Run}

Berdasarkan dari hasil tes Zig-zag Run diperoleh skor maksimal sebesar 68,80; skor minimal sebesar 32,66; mean (rata-rata) 50,00; median sebesar 50,60; modus sebesar 50,75; dan standar deviasi sebesar 10,00. Berdasarkan rumus kategori yang telah ditentukan, analisis data hasil kemampuan motorik atlet sepakbola di Akademi FC UNY ditinjau dari tes kelincahan adalah sebagai berikut:

Tabel 8. Distribusi Kemampuan Kelincahan

\begin{tabular}{|c|c|c|c|c|c|}
\hline No & \multicolumn{2}{|c|}{ Rumus } & Kategori & Frekuensi & Persentase $(\%)$ \\
\hline 1 & 65.00 & $>65$ & Sangat Tinggi & 2 & 8.33 \\
\hline 2 & 55.00 & $55-65$ & Tinggi & 5 & 20.83 \\
\hline 3 & 45.00 & $45-54$ & Sedang & 10 & 41.67 \\
\hline 4 & 35.00 & $35-44$ & Kurang & 5 & 20.83 \\
\hline 5 & $\leq 35$ & $<35$ & Sangat kurang & 2 & 8.33 \\
\hline \multicolumn{4}{|c|}{ Jumlah } & 24 & 100.00 \\
\hline
\end{tabular}

Berdasarkan dari hasil tabel di atas maka dapat dijelaskan secara keseluruhan hasil dari kemampuan kelincahan atlet sepakbola di akademi FC UNY sebanyak 2 atlet $(8,33 \%)$ berada pada kategori sangat tinggi, 5 atlet $(20,83 \%)$ berada pada kategori tinggi, 10 atlet $(41,67 \%)$ berada pada kategori sedang, 5 atlet $(20,83 \%)$ berada pada kategori kurang, 2 atlet $(8,33 \%)$ berada pada kategori sangat kurang. Jadi dapat disimpulkan bahwa mayoritas kelincahan atlet sepakbola di Akademi FC UNY berada pada kategori sedang sebesar 41,67 $\%$. Berdasarkan hasil diatas disajikan dalam bentuk diagram batang sebagai berikut:

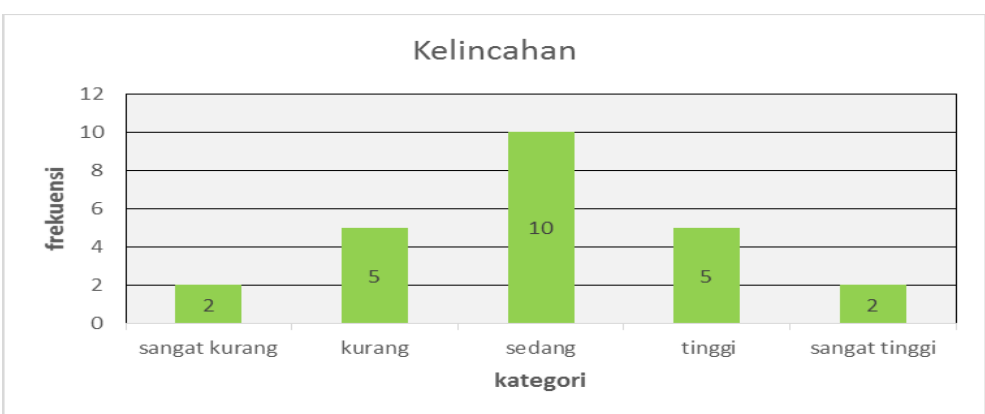

Gambar 4. Diagram Kemampuan Kelincahan 


\section{Komponen Koordinasi Tangan dan Mata yang diukur dengan Wall Pass}

Berdasarkan dari hasil tes Wall Pass diperoleh skor maksimal sebesar 72,93; skor minimal sebesar 31,46; mean (rata-rata) 50,00; median sebesar 48,42; modus sebesar 39,00; dan standar deviasi sebesar 10,00. Berdasarkan rumus kategori yang telah ditentukan, analisis data hasil kemampuan motorik atlet sepakbola di Akademi FC UNY ditinjau dari tes koordinasi Mata dan Tangan adalah sebagai berikut:

Tabel 9. Distribusi Kemampuan Koordinasi Mata dan Tangan

\begin{tabular}{|c|c|c|c|c|c|}
\hline No & \multicolumn{2}{|c|}{ Rumus } & Kategori & Frekuensi & Persentase $(\%)$ \\
\hline 1 & 65.00 & $>65$ & Sangat Tinggi & 2 & 8.33 \\
\hline 2 & 55.00 & $55-65$ & Tinggi & 5 & 20.83 \\
\hline 3 & 45.00 & $45-54$ & Sedang & 9 & 37.50 \\
\hline 4 & 35.00 & $35-44$ & Kurang & 7 & 29.17 \\
\hline 5 & $\leq 35$ & $<35$ & Sangat kurang & 1 & 4.17 \\
\hline \multicolumn{4}{|c|}{ Jumlah } & 24 & 100.00 \\
\hline
\end{tabular}

Berdasarkan dari hasil tabel di atas maka dapat dijelaskan secara keseluruhan hasil dari kemampuan koordinasi mata dan tangan atlet sepakbola di akademi FC UNY sebanyak 2 atlet $(8,33 \%)$ berada pada kategori sangat tinggi, 5 atlet $(20,83 \%)$ berada pada kategori tinggi, 9 atlet $(37,50 \%)$ berada pada kategori sedang, 7 atlet $(29,17 \%)$ berada pada kategori kurang, 1 atlet (4,17 \%) berada pada kategori sangat kurang. Jadi dapat disimpulkan bahwa mayoritas kemampuan koordinasi mata dan tangan atlet sepakbola di Akademi FC UNY berada pada kategori sedang sebesar 37,50 \%. Berdasarkan hasil diatas disajikan dalam bentuk diagram batang sebagai berikut:

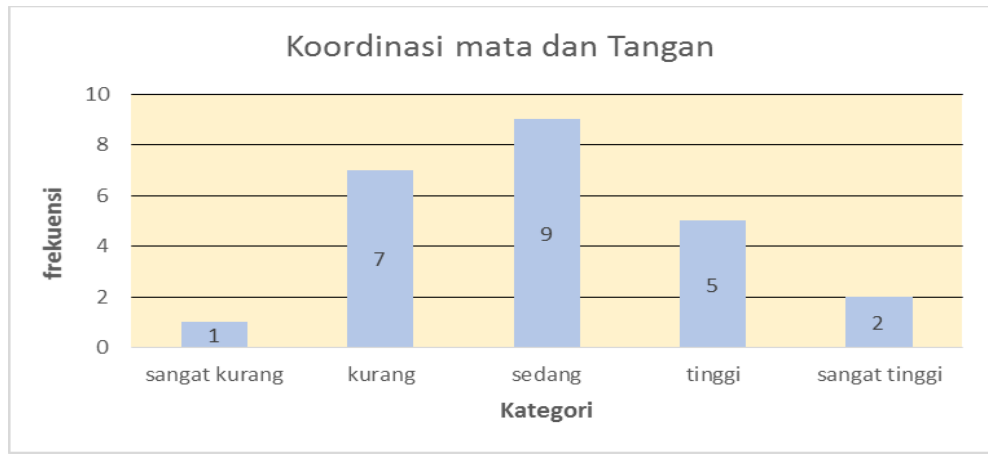

Gambar 5. Diagram Kemampuan Koordinasi Mata dan Tangan

\section{Komponen Power Otot Lengan yang diiukur dengan Medicine Ball Put}

Berdasarkan dari hasil tes Medicine Ball Put diperoleh skor maksimal sebesar 74,94; skor minimal sebesar 36,84; mean (rata-rata) 50,00; median sebesar 48,51; modus sebesar 44,21; dan standar deviasi sebesar 10,00. Berdasarkan rumus kategori yang telah ditentukan, analisis data hasil kemampuan motorik atlet sepakbola di Akademi FC UNY ditinjau dari tes kemampuan power otot lengan adalah sebagai berikut:

Tabel 10. Distribusi kemampuan Power Otot Lengan

\begin{tabular}{|c|c|c|c|c|c|}
\hline No & \multicolumn{2}{|c|}{ Rumus } & Kategori & Frekuensi & Persentase $(\%)$ \\
\hline 1 & 65.00 & $>65$ & Sangat Tinggi & 2 & 8.33 \\
\hline 2 & 55.00 & $55-65$ & Tinggi & 4 & 16.67 \\
\hline 3 & 45.00 & $45-54$ & Sedang & 8 & 33.33 \\
\hline 4 & 50.00 & $35-44$ & Kurang & 10 & 41.67 \\
\hline 5 & $\leq 35$ & $<35$ & Sangat kurang & 0 & 0.00 \\
\hline \multicolumn{4}{|c|}{ Jumlah } & 24 & 100.00 \\
\hline
\end{tabular}


Berdasarkan dari hasil tabel di atas maka dapat dijelaskan secara keseluruhan hasil dari kemampuan Power Otot Lengan atlet sepakbola di akademi FC UNY sebanyak 2 atlet $(8,33 \%)$ berada pada kategori sangat tinggi, 4 atlet $(16.67 \%)$ berada pada kategori tinggi, 8 atlet $(33,33 \%)$ berada pada kategori sedang, 10 atlet $(41,67 \%)$ berada pada kategori kurang, dan tidak ada atlet yang berada pada kategori sangat kurang $(00,00 \%)$. Jadi dapat disimpulkan bahwa mayoritas kemampuan Power Otot Lengan atlet sepakbola di Akademi FC UNY berada pada kategori kurang sebesar 41,67\%. Berdasarkan hasil diatas disajikan dalam bentuk diagram batang sebagai berikut:

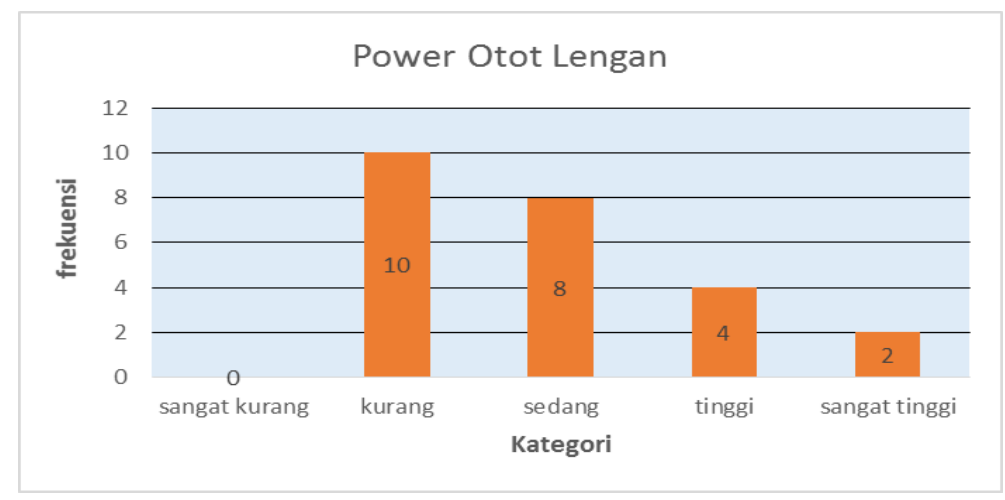

Gambar 6. Diagram Kemampuan Power Otot Lengan

\section{Komponen Kecepatan Diukur dengan Tes Lari 60 Yard Dash}

Berdasarkan dari hasil tes Lari 60 Yard Dash diperoleh skor maksimal sebesar 62,85; skor minimal sebesar 16,52; mean (rata-rata) 50,00; median sebesar 51,39; modus sebesar 50,76; dan standar deviasi sebesar 10,00. Berdasarkan rumus kategori yang telah ditentukan, analisis data hasil kemampuan motorik atlet sepakbola di Akademi FC UNY ditinjau dari tes kemampuan Kecepatan adalah sebagai berikut:

Tabel 11. Distribusi Kemampuan Kecepatan

\begin{tabular}{|c|c|c|c|c|c|}
\hline No & \multicolumn{2}{|c|}{ Rumus } & Kategori & Frekuensi & Persentase $(\%)$ \\
\hline 1 & 65.00 & $>65$ & Sangat Tinggi & 0 & 0.00 \\
\hline 2 & 55.00 & $55-65$ & Tinggi & 7 & 29.17 \\
\hline 3 & 45.00 & $45-54$ & Sedang & 11 & 45.83 \\
\hline 4 & 35.00 & $35-44$ & Kurang & 5 & 20.83 \\
\hline 5 & $\leq 35$ & $<35$ & Sangat kurang & 1 & 4.17 \\
\hline \multicolumn{4}{|c|}{ Jumlah } & 24 & 100.00 \\
\hline
\end{tabular}

Berdasarkan dari hasil tabel di atas maka dapat dijelaskan secara keseluruhan hasil dari kemampuan Kecepatan atlet sepakbola di akademi FC UNY tidak ada atlet yang berada pada kategori sangat tinggi $(00,00 \%), 7$ atlet $(29,17 \%)$ berada pada kategori tinggi, 11 atlet $(45,83 \%)$ berada pada kategori sedang, 5 atlet $(20,83 \%)$ berada pada kategori kurang, 1 atlet $(4,17 \%)$ berada pada kategori sangat kurang. Jadi dapat disimpulkan bahwa mayoritas kemampuan Kecepatan atlet sepakbola di Akademi FC UNY berada pada kategori Sedang sebesar 45,83 \%. Berdasarkan hasil diatas disajikan dalam bentuk diagram batang sebagaimana pada Gambar 7. 
MEDIKORA, Vol. 19 No. 2 Oktober 2020 - 108

Yudanto, Tifa Alfian

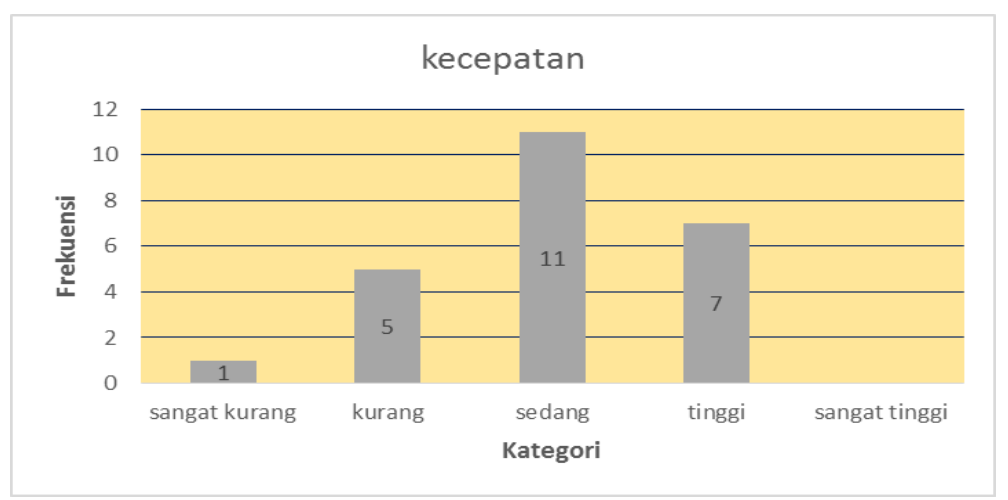

Gambar 7. Diagram Kemampuan Kecepatan.

\section{PEMBAHASAN}

Berdasarkan dari tes yang dilakukan para atlet sepakbola di Akademi FC UNY yang di dapatkan dari tes Barrow Motor Ability Tes, yang terdiri dari 6 tes antara lain: Standing Broad Jump, Wall Pass, Lari 60 Yard Dash, Zig-Zag Run, Medicine Ball Put, Soft Ball Throw. Berdasarkan dari hasil tes tersebut para atlet sepakbola di Akademi FC UNY memperoleh hasil 2 atlet $(8,33 \%)$ berada pada kategori sangat tinggi, 2 atlet $(8,33 \%)$ berada pada kategori tinggi, 10 atlet $(41,67 \%)$ berada pada kategori sedang, 8 atlet $(33,33 \%)$ berada pada kategori kurang, 2 atlet $(8,33 \%)$ berada pada kategori sangat kurang. Jadi, dapat disimpulkan bahwa kemampuan motorik atlet sepakbola di Akademi FC UNY tahun 2020 mayoritas berada pada kategori sedang $(41,67 \%)$. Hal ini menujukkan bahwa kemampuan motorik atau kemampuan gerak dasar yang merupakan gambaran umum kemampuan atlet dalam melakukan aktivitasnya berada pada kategori sedang. Hal ini disebabkan sebagian atlet memiliki pengalaman gerak yang hampir sama, namun memiliki tingkat keterampilan yang berbeda-beda. Dengan hasil tersebut maka perlu diperhatikan dan ditingkatkan kemampuan motorik para atlet sejak dini, karena akan membuat lebih besar peluang untuk terampil dalam bermain sepakbola.

Kemampuan motorik merupakan kualitas hasil gerak individu dalam melakukan gerak, tinggi gerak yang bukan gerak olahraga maupun gerak dalam olahraga atau kematangan penampilan keterampilan motorik. Makin tinggi kemampuan motorik seseorang maka dimungkinkan daya kerjanya akan menjadi lebih tinggi dan begitu sebaliknya. Oleh karena itu kemampuan gerak dapat dipandang sebagai keberhasilan di dalam melakukan tugas keterampilan gerak (Sukintaka, 2001: 47). Seseorang yang mempunyai kemampuan motorik yang baik, tentu akan mempunyai dasar atau landasan untuk melalukan ketrampilan secara khusus yang baik pula.

Adapun beberapa faktor yang mempengaruhi tingkat kemampuan motorik atlet sepakbola di Akademi FC UNY, diantaranya: 1) Waktu dan frekuensi latihan yang dilakukan setiap atlet berbeda-beda, ada yang berangkat latihan seminggu $3 \mathrm{kali}$, ada yang hanya berangkat 1 kali dalam seminggu. Sehingga program latihanya terganggu; 2) Sebagian atlet sepakbola di Akademi FC UNY sebelumnya belum pernah mengikuti Sekolah Sepak Bola (SSB) sehingga pengalaman geraknya kurang.

Dengan diketahuinya tingkat kemampuan motorik atlet sepakbola di Akademi FC UNY diharapkan kepada pelatih memberikan aktivitas atau program latihan yang tepat kepada atletnya untuk dapat mengembangkan kemampuan dirinya masing-masing. Jadi, semakin sering melakukan aktivitas atau program latihan, maka unsur-unsur motoriknya akan terus terlatih dan akan menambah kematangan gerak motoriknya.

Bagi pelatih setelah mengetahui tingkat kemampuan motorik atlet sepakbola di Akademi FC UNY, diharapkan agar hasil penelitian ini menjadi acuan dan juga pedoman 
bagi pelatih untuk menentukan program latihan yang tepat kepada atlet sepakbola sehingga membuat kemampuan motorik dari masing-masing atlet meningkat. Karena dengan program latihan yang tepat akan menambah kematangan gerak motoriknya masing-masing.

\section{Keterbatasan Penelitian}

Dalam penelitian ini penulis telah melakukan dengan semaksimal mungkin supaya hasil peneltian bisa berhasil dengan baik. Tetapi ada beberapa kekurangan dan kelemahan dalam penelitian ini, antara lain: 1) Faktor cuaca yang setiap sore rentan hujan deras, sehingga saat hujan deras menjadi kendala bagi para atlet untuk berangkat ke tempat penelitian; 2) Beberapa atlet berangkat terlambat karena jadwal jam pulang sekolah yang sampai sore hari. 3) Tidak diketahuinya kondisi atlet sebelum pelaksanaan tes, sehingga akan mempengaruhi hasil tes kemampuan motorik.

\section{SIMPULAN}

Berdasarkan dari hasil analisis data kemampuan motorik atlet sepakbola di Akademi FC UNY diketahui bahwa 2 atlet $(8,33 \%)$ berada pada kategori sangat tinggi, 2 atlet $(8,33 \%)$ berada pada kategori tinggi, 10 atlet $(41,67 \%)$ berada pada kategori sedang, 8 atlet $(33,33 \%)$ berada pada kategori kurang, 2 atlet $(8,33 \%)$ berada pada kategori sangat kurang. Jadi, dapat disimpulkan bahwa kemampuan motorik atlet sepakbola di Akademi FC UNY tahun 2020 mayoritas berada pada kategori sedang (41,67\%).

\section{Saran}

Bedasarakan dari kesimpulan di atas, saran yang diberikan oleh penulis antara lain:

Bagi Pelatih

Diharapkan untuk lebih mengoptimalkan waktu latihan dan hasil penelitian ini bisa dijadikan tolak ukur dalam memberikan program latihan kepada atlet sepakbola agar bisa tercapainya prestasi.

Bagi Atlet

Diharapkan atlet dapat meningkatkan kemampuan motoriknya agar kemampuan motoriknya selalu terjaga dan lebih termotivasi untuk bermain sepakbola dalam berbagai kompetisi.

\section{Bagi Akademi FC UNY}

Diharapkan pihak akademi juga memperhatikan para atletnya dan tidak lupa memberikan program latihan selingan untuk meningkatkat kemampuan motorikk atletnya demi menjadi atlet yang lebih baik dan bisa tercapainya prestasi.

\section{DAFTAR PUSTAKA}

Anas Sudijono. (2007). Pengantar Statistik Pendidikan. Jakarta: Grafindo Persada.

Beltasar Tarigan. (2001). Pendekatan Keterampilan Taktis dalam Pembelajaran Sepakbola. Jakarta: Depdiknas.

Djoko Pekik Irianto, (2002). Dasar Kepelatihan. Jogyakarta: FIK UNY.

Elene Elyonara, (2012). Kemampuan Motorik Peserta Ekstrakurikuler Bolavoli di SMP Negeri 3 Gamping. Jogyakarta: FIK UNY.

Elizabeth B. Hurlock, (1980). Perkembangan Gerak Anak. Jakarta: Erlangga.

Febri Nurcahyo. (2013). Tingkat Kemampuan Motorik Peserta Didik Yang Mengikuti Ekstrakurikuler Sepakbola di SMP Negeri 3 Godean Sleman. Yogyakarta: FIK UNY. 
MEDIKORA, Vol. 19 No. 2 Oktober 2020 - 110

Yudanto, Tifa Alfian

Harsuki. (2003). Perkembangan Olahraga Terkini Kajian Para Pakar. Jakarta: PT. Raja Grafindo Perkasa.

Hurlock, E. B. (1980). Perkembangan Gerak Anak. Jakarta: Erlangga.

Kiram, Y. (1992). Belajar Motorik. Jakarta: Depdikbud.

Ma'mun, A. \& Saputra, Y. M. (2000). Perkembangan Gerak dan Belajar Gerak. Jakarta: Depdikbud.

Muthohir dan Gusril. (2004). Perkembangan Motorik Pada Masa Anak-anak. Jakarta: Depdikbud RI.

Mochamad Sajoto, (1988). Pembinaan Kondisi Fisik Dalam Olahraga. Jakarta: Depdikbud, Proyek Pengembangan Lembaga Pendidikan Tenaga Kependidikan (P2LPTK).

Nurhasan. (2000). Tes Dan Pengukuran Pendidikan Olahraga. Bandung: Universitas Pendidikan Indonesia.

Rini, E. (2007). Perkembangan Motorik (diktat). Yogyakarta: FIK UNY.

Rusli Lutan. (1988). Belajar Ketrampilan Motorik, Pengantar Teori dan Metode. Jakarta: Departemen P\&K Dirjen Dikti Proyek Pengembangan Lembaga Pendidikan dan Tenaga Kependidikan.

Saifuddin Azwar. (2005). Sikap Manusia: Teori dan Pengukurannya. Yogyakarta: Pustaka Pelajar.

Scheunemann, Timo (2005). Dasar Sepak Bola Modern untuk pemain dan pelatih. Malang: Dioma

Setyo Nugroho. (2005). Status Kemampuan Motorik Umum Siswa Sekolah Sepakbola Di Kabupaten Sleman. Jurnal Ilmu Keolahragaan. Yogyakarta: FIK UNY.

Sucipto, Dkk. (2000). Sepakbola. Jakarta: Departemen Pendidikan Nasional, Direktoral Jendral Pendidikan Dasar dan Menengah

Sugiyono. (2006). Metode Penelitian Pendidikan. Bandung: Alfabeta.

Suharsimi Arikunto. (2010). Prosedur Penelitian. Jakarta: Rineka Cipta.

Sukadiyanto. (1997). Penentuan tahap Kemampuan Motorik Anak Sekolah Dasar (Majalah Ilmiah).Yogyakarta: FPOK IKIP.

Sukintaka. (2001). Teori Pendidikan Jasmani. Solo: Esa Grafika.

Sulistiyono. (2010). Somatotype Penjaga Gawang Unit Kegiatan Mahasiswa Sepakbola UNY Tahun Pelatihan 2010/2011. Jurnal Olahraga Prestasi, Volume 6, Nomor 2, Juli 2010. Yogyakarta: FIK UNY

Soekatamsi. 2000. Permainan Sepakbola I. Jakarta: Depdikbud Direktorat Jendral Pendidikan guru dan Tenaga Teknis. 
MEDIKORA, Vol. 19 No. 2 Oktober 2020 - 111

Yudanto, Tifa Alfian

Toho Cholik \& Gusril. (2004). Pembelajaran Motorik. Diakses dari http://taraprahas.blogspot.com/pembelajaran-motorik.html. Pada tanggal 20 februari 2020 .

Yhana Pratiwi dan M. Kristanto. (2015). Upaya Maningkatkan Kemampuan Motorik Kasar (Keseimbangan Tubuh) Anak Melalui Permainan Tradisional Engklek di Kelompok B Tunas Rimba II Tahun Ajaran 2015/2015. Jurnal Ilmu Keolahragaan. PAUDIA.

Yudanto. (2016). Upaya Mengembangkan Kemampuan Motorik Anak Prasekolah. Jurnal Pendidikan Jasmani Indonesia. Volume 3, Nomor 3, November 2016. Yogyakarta: FIK UNY

Yusuf, M. (2014). Metode Penelitian: Kuantitatif, Kualitatif dan Gabungan. Jakarta: Prenadamedia Group. 